\title{
Composition and cell wall content of diets selected by Roe deer, Red deer, Highland cattle and Konik ponies
}

\author{
SE van Wieren \\ Department of Terrestrial Ecology and Nature Conservation, Wageningen Agricultural University, Po Box 8080 , \\ 6700 DD Wageningen, Netherlands
}

Based on described differences in morphological characteristics and differences in the capacity to digest fiber (Hofmann, 1973, The Ruminant Stomach) it can be expected that, within the class of ruminants, concentrate selectors or browsers (Roe deer) will prefer to comsume less fibrous plant species than bulk and roughage feeders or grazers (Highland cattle) while intermediate feeders (Red deer) should take an intermediate position. As a large hindgut fermenter the horse (Konik pony) is expected to compare well with the ox.

To test this idea diet composition was studied in large forest enclosures. Mixed samples of fresh faeces were collected monthly of the 4 mentioned species. Diet composition was estimated by means of counting and measuring surface area of epidermal fragments in faeces. Simultaneously grabsamples of plant species eaten were collected and analyzed for cell wall content. The cell wall content of the diets consumed was calculated using the results of the faecal analysis. Monthly results were averaged per season and final results are presented as percentage monocots and as amount of cell wall content in the diet.

Roe deer consumed much less monocots than both Highland cattle and Red deer while Red deer were intermediate only in spring and summer. Of all species the Konik ponies consumed most monocots in 3 seasons. The order of cell wall content in the diet was Roe deer < Red deer < Highland cattle < Konik ponies in all seasons, differences between cattle and ponies being small.

It is concluded that Roe deer indeed prefer less fibrous food plants and select a diet lower in fiber than Highland cattle while Red deer, on average, are in between.

Ponies strongly prefer monocots and can be classified as real grazers, even more so as free ranging cattle.

\begin{tabular}{|c|c|c|c|c|c|c|c|c|}
\hline & & noco & diet & & cell & conte & f die & DM) \\
\hline & SP & SU & $A U$ & WI & SP & SU & $A U$ & WI \\
\hline Roe deer & 10 & 0 & 5 & 23 & 28 & 30 & 46 & 50 \\
\hline Red deer & 38 & 20 & 53 & 47 & 42 & 42 & 55 & 53 \\
\hline Cattle & 60 & 51 & 58 & 43 & 51 & 51 & 57 & 58 \\
\hline Ponies & 92 & 81 & 50 & 70 & 52 & 60 & 59 & 60 \\
\hline
\end{tabular}

